\title{
Oxide dispersion-strengthened steel PM2000 after dynamic plastic deformation: nanostructure and annealing behaviour
}

\author{
Z. B. Zhang ${ }^{1,2,5, \star}$, N. R. Tao ${ }^{3,5}$, O. V. Mishin ${ }^{1,5}$, and W. Pantleon ${ }^{4,5}$ \\ ${ }^{1}$ Section for Materials Science and Advanced Characterization, Department of Wind Energy, Technical University of Denmark, Risø \\ Campus, 4000 Roskilde, Denmark \\ ${ }^{2}$ School of Materials, University of Manchester, Manchester M13 9PL, UK \\ ${ }^{3}$ Institute of Metal Research, Chinese Academy of Science, Shenyang 110016, China \\ ${ }^{4}$ Section for Materials and Surface Engineering, Department of Mechanical Engineering, Technical University of Denmark, \\ 2800 Kgs. Lyngby, Denmark \\ ${ }^{5}$ Sino-Danish Center for Education and Research, Aarhus, Denmark
}

Received: 1 December 2015

Accepted: 24 February 2016 Published online:

7 March 2016

(C) The Author(s) 2016. This article is published with open access at Springerlink.com

\begin{abstract}
The microstructure, texture and mechanical properties have been studied in PM2000 compressed via dynamic plastic deformation to a strain of 2.1. It is found that dynamic plastic deformation results in a duplex $\langle 111\rangle+\langle 100\rangle$ fibre texture and refines the initial microstructure by nanoscale lamellae, which substantially increases the strength of the material, but decreases its thermal stability. In the as-deformed microstructure, the stored energy density is found to be higher in $\langle 111\rangle$-oriented regions than in $\langle 100\rangle$-oriented regions. Recovery during annealing at $715{ }^{\circ} \mathrm{C}$ reduces the energy stored in the deformed microstructure. This reduction is more pronounced in the $\langle 111\rangle$-oriented regions. Orientation-dependent recrystallisation takes place in the recovered microstructure, leading to strengthening of the $\langle 111\rangle$ fibre texture component at the expense of the $\langle 100\rangle$ fibre texture component.
\end{abstract}

\section{Introduction}

Oxide dispersion-strengthened (ODS) steels are promising structural materials for the next-generation fission and fusion reactors because of their excellent resistance to both irradiation damage and high-temperature creep [1, 2]. It has been reported that irradiation tolerance in steels and other materials may further be improved if their microstructures are refined to the submicrometre or nanometre scale [3, 4]. One well-known way to refine the microstructure is via plastic deformation when original grains are subdivided by deformation-induced dislocation boundaries [5, 6]. For example, structural refinement in the range of $0.3-0.6 \mu \mathrm{m}$ was produced by equal channel angular extrusion (ECAE) in a

Address correspondence to E-mail: : zhenbo.zhang@manchester.ac.uk 
ferritic/martensitic steel T91 and a 12Cr ODS steel [3, 7]. The swelling rate during the irradiation of the submicrometre-grained T91 steel after warm ECAE to a strain of 2.3 was found to be three times lower than that of a coarse-grained sample [3].

Compared to the structural refinement achieved by ECAE in [3, 7], a much finer boundary spacing can be obtained if the deformation is performed at high strain rates. For instance, a lamellar structure with a boundary spacing of only $0.1 \mu \mathrm{m}$ developed in a modified 9Cr-1Mo steel (T91) [8] due to compression via dynamic plastic deformation (DPD) [9] to a strain of 2.3 at a strain rate of $10^{2}-10^{3} \mathrm{~s}^{-1}$. A more effective structural refinement by DPD as compared to lowstrain-rate deformation has also been documented for other metals such as aluminium and nickel $[10,11]$. It is reasonable to expect that DPD can also be very effective in refining the microstructures of ODS steels. The primary aim of this work is therefore to investigate the effect of compression by DPD on the microstructure of an ODS material. For this purpose, we chose to study PM2000 [12], an iron-based ODS alloy developed for application in power plants. Since nanostructured materials produced by deformation are in general less thermally stable than their less-refined counterparts [13], the annealing behaviour of DPD-processed PM2000 is also investigated in the present work. Both transmission electron microscopy (TEM) and electron backscatter diffraction (EBSD) are used here to enable a detailed microstructural analysis of changes taking place during DPD and subsequent annealing. The microstructural analysis is complemented by hardness measurements and tensile tests.

\section{Experimental}

The nominal chemical composition of PM2000 [12] is shown in Table 1 . The material was received in the form of a hot-extruded rod with a diameter of $13 \mathrm{~mm}$. Two cylindrical specimens with a diameter of $6 \mathrm{~mm}$ and height of $9 \mathrm{~mm}$ were then machined with their cylinder axis along the extrusion direction (ED),

Table 1 Nominal chemical composition (wt\%) of PM2000 [12]

\begin{tabular}{lllll}
\hline $\mathrm{Cr}$ & $\mathrm{Al}$ & $\mathrm{Ti}$ & $\mathrm{Y}_{2} \mathrm{O}_{3}$ & $\mathrm{Fe}$ \\
\hline 20 & 5.5 & 0.5 & 0.5 & Balance
\end{tabular}

see Fig. 1a. The specimens were compressed at room temperature by DPD in five steps to a final thickness of $1.1 \mathrm{~mm}$, which corresponds to an equivalent strain, $\varepsilon_{\mathrm{vM}}=\ln \left(h_{0} / h\right)$ of 2.1 , where $h_{0}$ is the initial height, and $h$ is the final sample thickness, respectively. The diameter of the compressed samples was about $17.2 \mathrm{~mm}$ (Fig. 1b). Parts of the deformed samples were then annealed for $1 \mathrm{~h}$ at different temperatures between 500 and $800{ }^{\circ} \mathrm{C}$ and for different time intervals at $715{ }^{\circ} \mathrm{C}$.

TEM foils from the longitudinal section in the asreceived sample and from the longitudinal section near the centre of the compressed disc (see Fig. 1c) were prepared by twin jet electropolishing in a solution of ethanol (70 vol\%), water (12 vol\%), 2-butoxy-ethanol (10 vol\%), and perchloric acid (8 vol\%). TEM images were obtained using a JEOL 2000FX transmission electron microscope operating at $200 \mathrm{kV}$.

EBSD analysis was performed using a Zeiss Supra 35 field emission gun scanning electron microscope equipped with a Channel 5 system. In the deformed sample, several regions with a total area of $750 \mu \mathrm{m}^{2}$ were investigated by the EBSD technique. Larger areas, at least $2500 \mu \mathrm{m}^{2}$, were investigated in each annealed sample. Due to the limited angular resolution of this technique [14, 15], misorientation angles less than $2^{\circ}$ were not considered in the analysis. Boundaries with misorientation angles $\theta$ between $2^{\circ}$ and $15^{\circ}$ were defined as low-angle boundaries (LABs), while boundaries with misorientation angles larger than $15^{\circ}$ were classified as high-angle boundaries (HABs). Recrystallised grains in the orientation maps were defined as regions at least partly surrounded by HABs, having an equivalent circular diameter (ECD) above $3 \mu \mathrm{m}$ and an internal point-topoint misorientation below $2^{\circ}$ [16]. Area fractions of different fibre texture components were calculated allowing a $10^{\circ}$ orientation deviation from the exact $\langle$ uvw $\rangle$ fibres. These area fractions are representative of volume fractions.

The boundary area density $S_{V}$ was also determined from the EBSD data $[17,18]$, and the energy density stored in the form of boundaries in the deformed or recovered microstructure was estimated as $u=\gamma S_{V}$. The specific boundary energy of HABs was assumed to be $\gamma_{\mathrm{HAB}}=617 \mathrm{~mJ} / \mathrm{m}^{2}$ [19]. The specific boundary energy of LABs with misorientation angles $\theta<\theta_{\text {cr }}=15^{\circ}$ was calculated using the Read-Shockley equation $[20,21]$ : 
Figure 1 Schematic illustration of samples before and after DPD: a initial sample; $\mathbf{b}$ sample after DPD to a strain of 2.1; c locations of specimens used for microstructural examinations and mechanical tests after DPD.

Figure 2 Microstructure of the as-received PM2000 sample: a TEM image and b orientation map showing crystallographic directions along the ED. The colour code is given in the inset. In b, white and black lines represent LABs and HABs, respectively. (a)

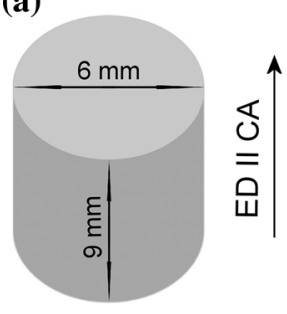

(b)

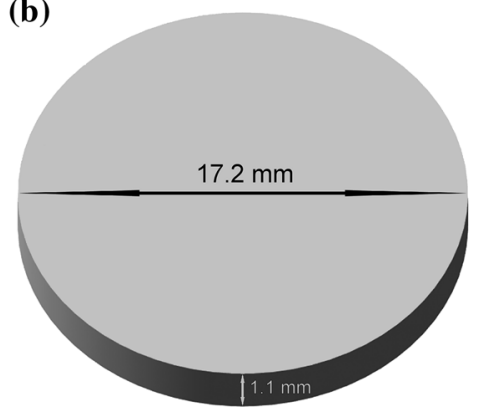

(c)

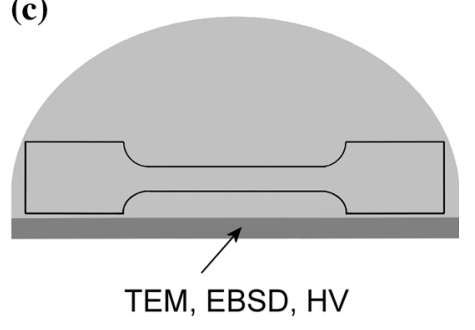

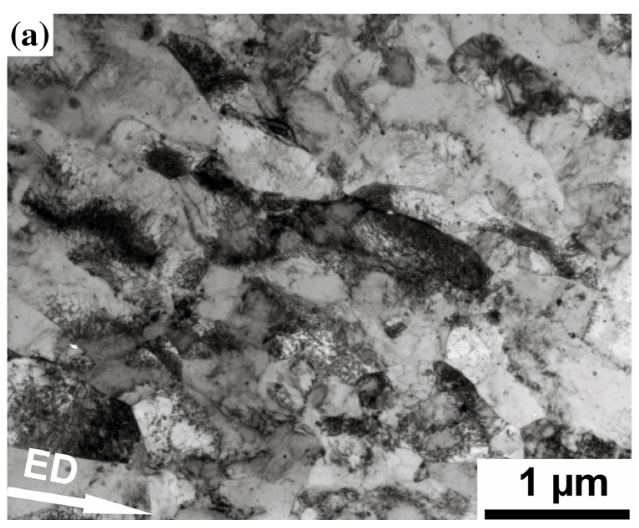

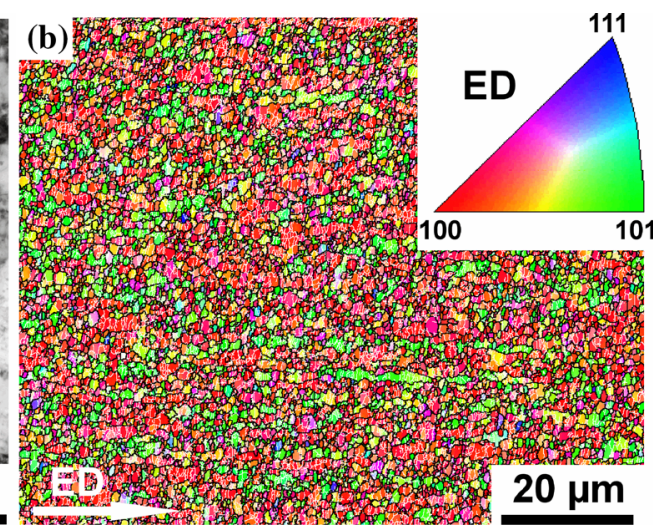

$\gamma_{\mathrm{LAB}}=\gamma_{\mathrm{HAB}} \frac{\theta}{\theta_{\mathrm{cr}}}\left(1-\ln \left(\frac{\theta}{\theta_{\mathrm{cr}}}\right)\right)$

Vickers hardness was determined using a load of $1 \mathrm{~kg}$ with a $10 \mathrm{~s}$ dwell time. Dog-bone shaped specimens with a gauge section of $5 \times 1 \times 0.5 \mathrm{~mm}^{3}$ prepared from the as-received sample and the compressed sample were tensile tested at room temperature using an Instron 5848 MicroTester with an initial strain rate of $5 \times 10^{-3} \mathrm{~s}^{-1}$. The tensile axis was aligned along the ED for the as-received condition and perpendicular to the compression axis (CA) for the compressed sample. A MTS LX300 laser extensometer was used for measuring strain during the test.

\section{Results}

\section{As-received PM2000}

A bright field TEM image in Fig. 2a shows that the as-received material is characterised by a high dislocation density and contains well-dispersed oxide nanoparticles identified in our previous work [22] as orthorhombic yttrium-aluminium oxide $\mathrm{YAlO}_{3}$. The orientation map obtained by EBSD in Fig. 2b demonstrates both almost equiaxed and highly elongated grains. As is evident from the colour code in the inset, most grains have either $\langle 100\rangle$ or $\langle 110\rangle$ directions aligned along the extrusion direction. Approximately $50 \%$ of all boundaries in this material are HABs. The average spacing $d_{\theta>2^{\circ}}$, defined as the mean distance between boundaries with misorientation angles greater than $2^{\circ}$, is $580 \mathrm{~nm}$, and the HAB spacing is $940 \mathrm{~nm}$ as measured along the ED.

The hardness of this material is $332 \mathrm{HV} 1$. The tensile test reveals a combination of moderate ultimate tensile strength (UTS) of $932 \mathrm{MPa}$ and reasonably high ductility (see Fig. 3) with an elongation to failure of about $15 \%$.

\section{PM2000 after compression by DPD}

A characteristic deformation structure with lamellar boundaries almost perpendicular to the CA is observed after DPD (see Fig. 4). The mean thickness of the lamellae measured in TEM images (see an example in Fig. 4a) is $72 \mathrm{~nm}$, and the $d_{\theta>2^{\circ}}$ measured along the CA in the orientation map in Fig. $4 \mathrm{~b}$ is $76 \mathrm{~nm}$, i.e. after compression by DPD the sample is 
truly nanostructured. The fraction of HABs in this material is $46 \%$.

The orientation map in Fig. $4 \mathrm{~b}$ indicates that lamellae are arranged in bands with either $\langle 100\rangle$ directions (red in Fig. 4b) or $\langle 111\rangle$ directions (blue in Fig. $4 \mathrm{~b}$ ) along the CA. The texture of the DPD-processed sample can therefore be described as a duplex $\langle 111\rangle+\langle 100\rangle$ fibre texture.

Compared to the as-received condition, the hardness and the UTS of the DPD-processed sample are increased to $443 \mathrm{HV} 1$ and $1480 \mathrm{MPa}$, respectively. The elongation to failure of PM2000 after DPD is only $3 \%$ (see Fig. 3).

\section{PM2000 annealed after compression by DPD}

\section{Softening}

The effect of annealing was first evaluated by conducting Vickers hardness measurements after annealing at different temperatures for $1 \mathrm{~h}$. Results of these measurements (see Fig. 5) demonstrate that

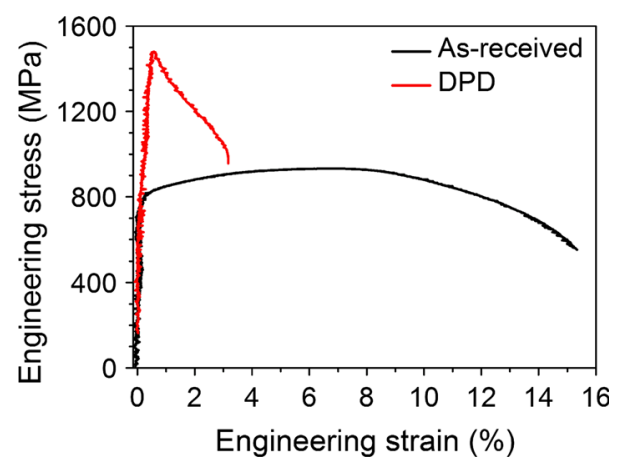

Figure 3 Stress-strain curves for PM2000 in the as-received condition and after compression by DPD. Minor horizontal oscillations are an artefact of the strain measurement. annealing for $1 \mathrm{~h}$ at temperatures up to $500{ }^{\circ} \mathrm{C}$ does not appreciably affect the hardness reached by DPD. Within the temperature range, $500{ }^{\circ} \mathrm{C}<T \leq 700{ }^{\circ} \mathrm{C}$, the material softens gradually to $383 \mathrm{HV} 1$. A sharp drop in hardness is observed when the annealing temperature exceeds $700{ }^{\circ} \mathrm{C}$ (Fig. 5). For all the samples annealed in the temperature range, $715{ }^{\circ} \mathrm{C} \leq \mathrm{T} \leq 800{ }^{\circ} \mathrm{C}$, the hardness is below $300 \mathrm{HV} 1$.

As the transition between slight and large reductions in hardness occurs at $715^{\circ} \mathrm{C}$, the microstructural evolution during annealing was investigated at this temperature. Samples annealed for 10, 20 and $80 \mathrm{~min}$ at $715^{\circ} \mathrm{C}$ were chosen for a detailed microstructural analysis.

\section{Evolution of microstructure and texture}

TEM images and orientation maps for the annealed samples selected for microstructural investigations are presented in Figs. 6 and 7, respectively. The TEM images provide evidence that the oxide nanoparticles have a certain pinning effect on dislocations (Fig. 6a) and migrating boundaries (Fig. 6b). The microstructure after $10 \mathrm{~min}$ of annealing at $715^{\circ} \mathrm{C}$ is considerably coarser $\left(d_{\theta>2^{\circ}}=176 \mathrm{~nm}\right)$ than that after DPD (see Fig. 8a). This coarsening, however, does not change the lamellar morphology induced by DPD (see Fig. 7a). The fraction of HABs after $10 \mathrm{~min}$ is similar to that in the as-deformed condition (see Fig. 8b). Recrystallisation nuclei are very rare after $10 \mathrm{~min}$ (one nucleus is marked by an arrow in Fig. 7a), and the area fraction of recrystallised material $f_{\mathrm{RX}}$ is only $1 \%$.

After 20 min of annealing, $f_{\mathrm{RX}}$ is much larger, $68 \%$, and the average boundary spacing $d_{\theta>2^{\circ}}$ is increased to $750 \mathrm{~nm}$ (Figs. 7b, 8). After annealing for $80 \mathrm{~min}$,
Figure 4 Microstructure of PM2000 after compression by DPD: a TEM image and b orientation map showing crystallographic directions along the CA. The colour code is given in the inset. In $\mathbf{b}$, white and black lines represent LABs and HABs, respectively.
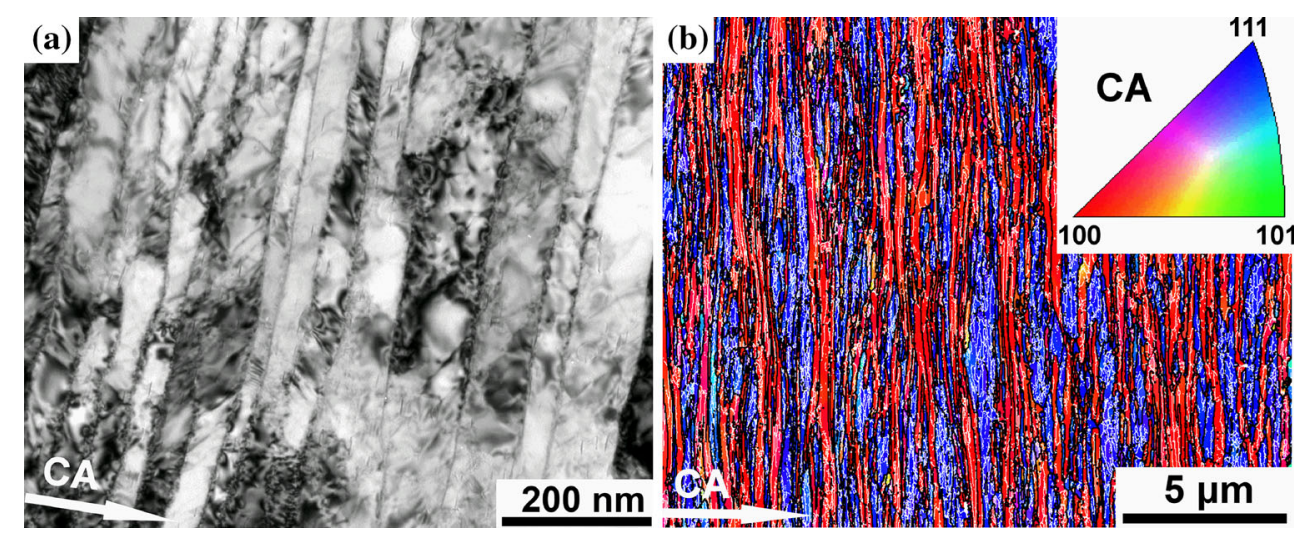
the material is almost fully recrystallised $\left(f_{\mathrm{RX}}=97 \%\right)$ with $d_{\theta>2^{\circ}}=3750 \mathrm{~nm}$ (Figs. 7c, 8a, c). The fraction of LABs in this almost fully recrystallised microstructure is only $19 \%$ (Fig. 8b). The orientation maps demonstrate that the majority of recrystallised grains have a $\langle 111\rangle$ direction along the CA (blue in Fig. 7). In the sample annealed for $80 \mathrm{~min}$ (Fig. 7c), such $\langle 111\rangle$ oriented grains occupy $67 \%$ of the area.

Figure 9 presents an example of the non-recrystallised regions still present in the microstructure after $80 \mathrm{~min}$ of annealing. A very fine lamellar structure with an average lamellae thickness of $165 \mathrm{~nm}$ and a high density of dislocations are preserved in such non-recrystallised regions. Analysis of selected area diffraction patterns from several lamellae in Fig. 9b indicates that their orientations belong to the $\langle 100\rangle$ fibre texture.

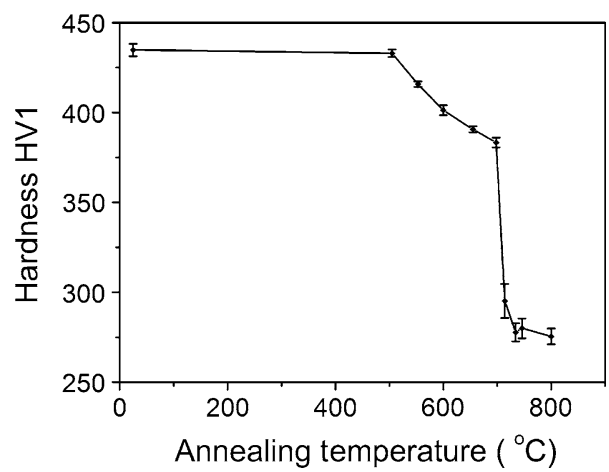

Figure 5 Vickers hardness of PM2000 compressed by DPD to a strain of 2.1 and annealed at different temperatures for $1 \mathrm{~h}$. Error bars represent the standard deviation of the distribution.
The evolution of crystallographic texture measured by the EBSD technique in large sample areas is illustrated by inverse pole figures (IPFs) in Fig. 10. It is seen that the duplex $\langle 111\rangle+\langle 100\rangle$ fibre texture formed by DPD evolves during annealing into a welldefined $\langle 111\rangle$ fibre texture, whereas the strength of the $\langle 100\rangle$ fibre texture component decreases. Considering the area fractions of the individual fibre texture components in Fig. 11, it is apparent that during recrystallisation the $\langle 111\rangle$ fibre strengthens at the expense of the $\langle 100\rangle$ fibre, i.e. recrystallisation in PM2000 after compression by DPD is orientationdependent.

\section{Discussion}

\section{Nanostructure and strength}

Compression of PM2000 by DPD to a strain of 2.1 results in nanoscale lamellar structures with a boundary spacing of $72 \mathrm{~nm}$ as measured along the CA using TEM. This spacing is considerably smaller than the value of $98 \mathrm{~nm}$ measured in a modified $9 \mathrm{Cr}-$ 1 Mo steel compressed by DPD to a similar strain [8]. The smaller spacing in PM2000 as compared to the modified 9Cr-1Mo steel may be attributed to a finer initial microstructure in PM2000 before DPD as well as to the presence of oxide nanodispersoids, which could make structural refinement of this ODS alloy more efficient. Such accelerated structural refinement has previously been reported for rolled aluminium containing small alumina particles [23]. Similar to other compressed body-centred cubic materials,
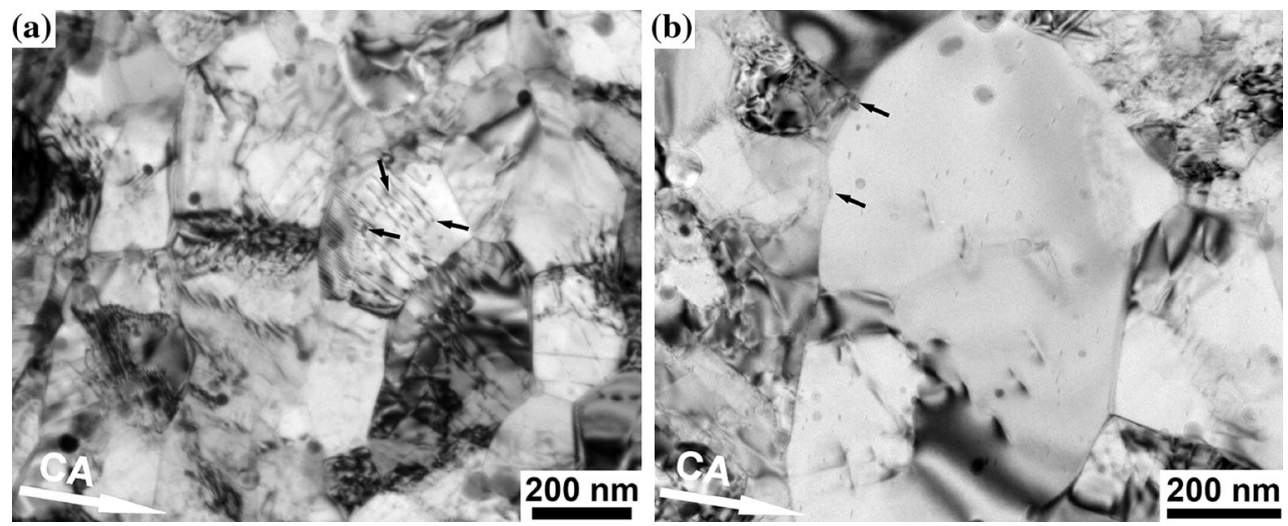

Figure 6 TEM images of PM2000 after compression by DPD and subsequent annealing at $715{ }^{\circ} \mathrm{C}$ for 10 min. Small black arrows indicate dislocations in (a) and a migrating boundary in (b) pinned by oxide nanoparticles. 
Figure 7 Orientation maps for PM2000 after compression by DPD and subsequent annealing at $715^{\circ} \mathrm{C}$ for a $10 \mathrm{~min}$, b $20 \mathrm{~min}$ and c $80 \mathrm{~min}$. The colours correspond to crystallographic directions along the $\mathrm{CA}$ according to the inverse pole figure in the lower right corner. One recrystallised grain found after $10 \mathrm{~min}$ of annealing is encircled in a. White and black lines represent $\mathrm{LABs}$ and HABs, respectively. In each map, the $\mathrm{CA}$ is horizontal.
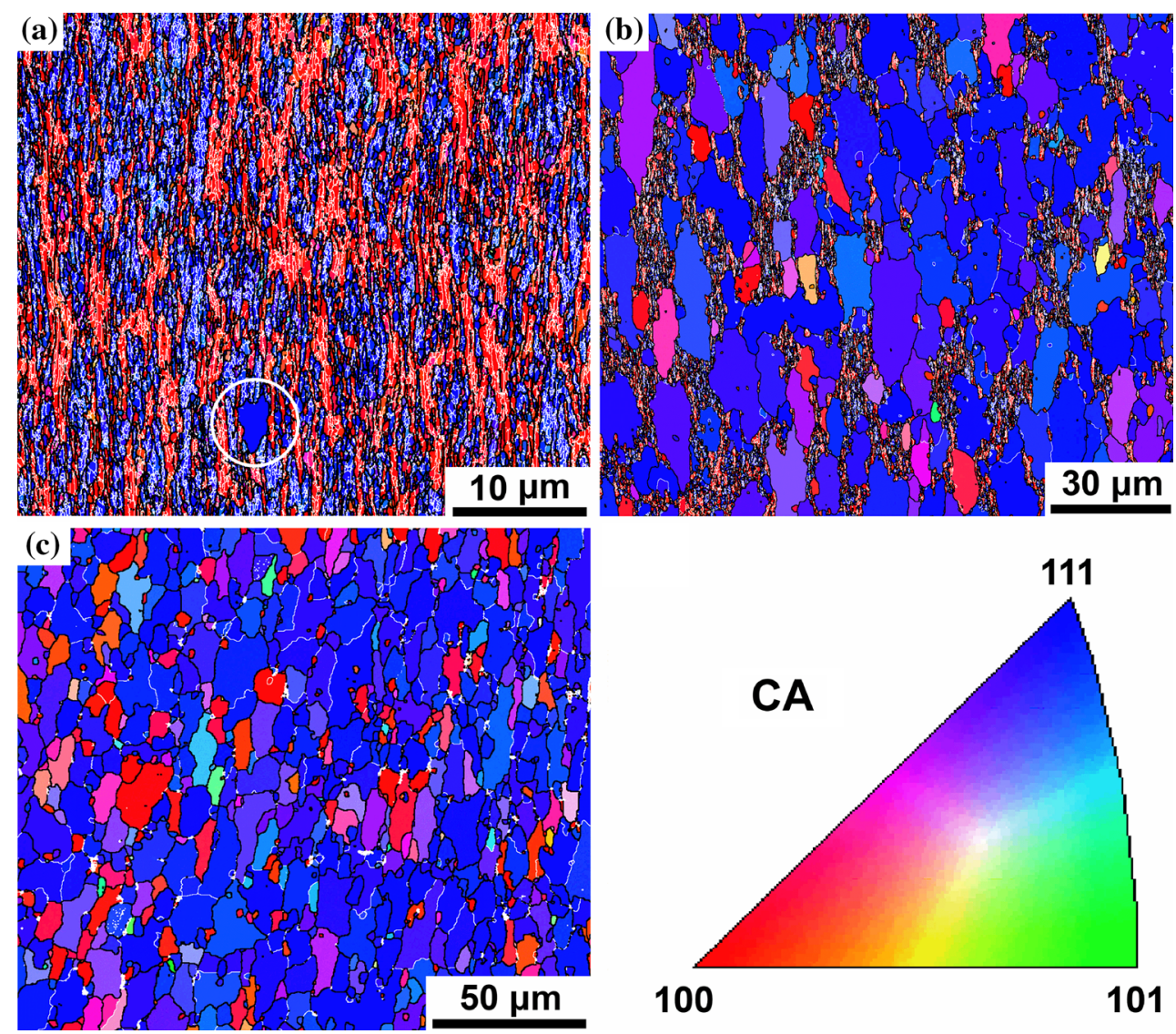

PM2000 develops a strong duplex $\langle 111\rangle+\langle 100\rangle$ fibre texture during compression by DPD [7, 8, 24, 25].

The structural refinement by DPD makes PM2000 very hard and increases the UTS to $1480 \mathrm{MPa}$, which is significantly higher than the strength in the as-received condition and the UTS previously reported for PM2000 and other ODS steels such as mechanically alloyed MA956 and MA957 [26]. The strength of PM2000 after DPD is also higher than that of the modified 9Cr-1Mo steel processed by DPD to a similar strain, in which the UTS is only $1240 \mathrm{MPa}$ [8]. The higher strength in the DPD-processed PM2000 is consistent with the finer microstructure in this material. The increase in strength of PM2000 during DPD is accompanied by a significant reduction in ductility-a phenomenon which has previously been observed in many cold-deformed materials due to their limited capacity of work hardening [8, 27, 28].

\section{Recovery and recrystallisation}

Our investigation demonstrates that the nanostructure formed in PM2000 after compression by DPD is fairly stable during annealing for $1 \mathrm{~h}$ at temperatures as high as $500{ }^{\circ} \mathrm{C}$. However, annealing at temperatures higher than $500{ }^{\circ} \mathrm{C}$ makes the nanostructure unstable, as follows from the significant softening observed in Fig. 5 after annealing above $500{ }^{\circ} \mathrm{C}$. The shape of the hardness curve in Fig. 5 implies that the deformed microstructure only recovers within the temperature range from 500 to $700{ }^{\circ} \mathrm{C}$, whereas at temperatures higher than $700{ }^{\circ} \mathrm{C}$ pronounced recrystallisation takes place. It is therefore apparent that compared to the as-received condition, in which no evidence of recrystallisation was observed even after annealing $1100{ }^{\circ} \mathrm{C}$ for $1 \mathrm{~h} \mathrm{[29],} \mathrm{the} \mathrm{thermal} \mathrm{sta-}$ bility of the nanostructured condition is considerably reduced.

The microstructural observations made in PM2000 after DPD and annealing at $715^{\circ} \mathrm{C}$ indicate that during recovery (within the first $10 \mathrm{~min}$ of annealing) the microstructure coarsens despite a certain pinning effect imposed by nanoparticles on boundary migration. The coarsened microstructure largely retains the lamellar morphology and maintains a similar proportion of LABs and HABs to that 
Figure 8 Microstructural parameters (from EBSD data) of PM2000 after compression by DPD and subsequent annealing at $715^{\circ} \mathrm{C}$ : a boundary spacing $d_{\theta>2^{\circ}}$ measured along the $\mathrm{CA}$; b fractions of HABs and LABs; $c$ fraction of recrystallised material.
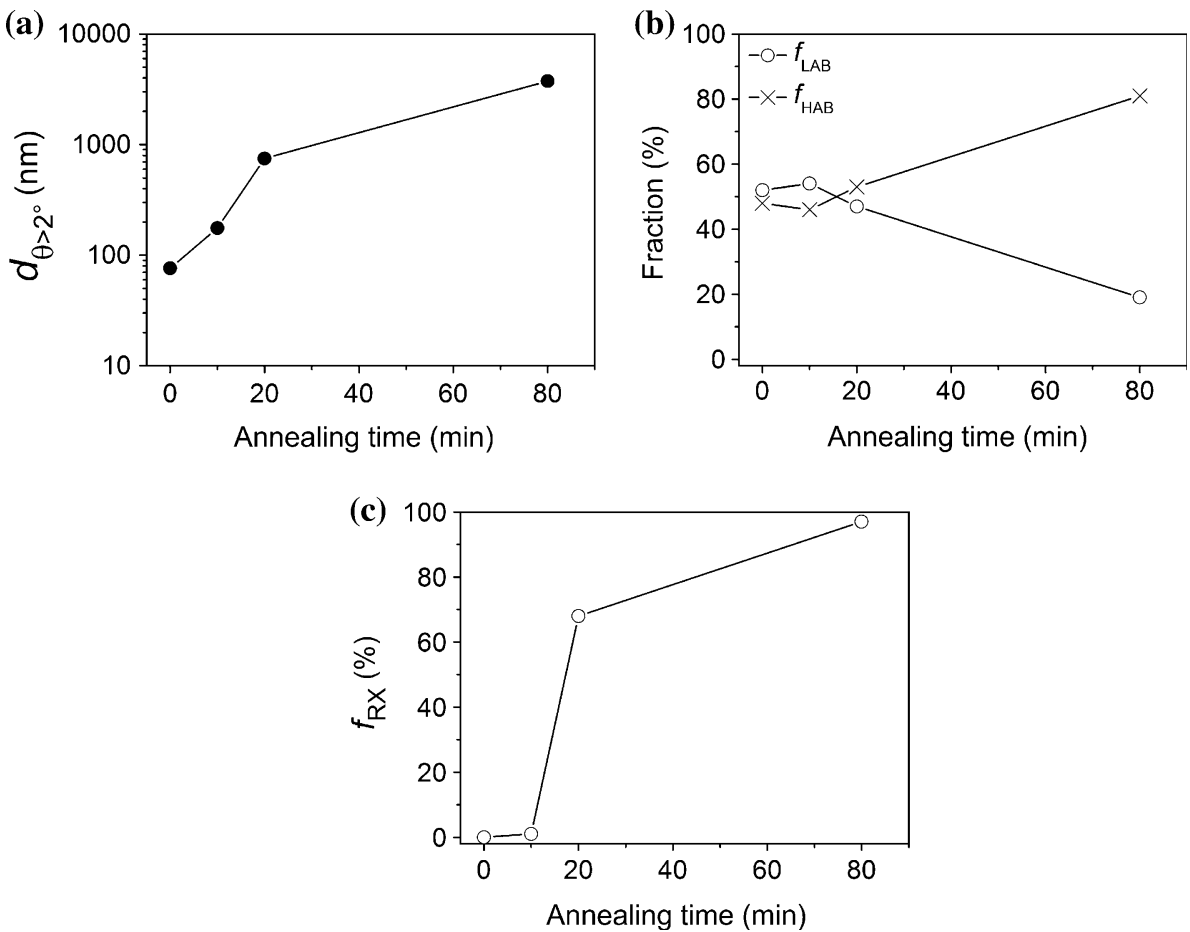

observed in the as-deformed microstructure (see Fig. 8b). Although the density of interior dislocations was not determined quantitatively in the present experiment, it is apparent that the dislocation density in the TEM images taken after $10 \mathrm{~min}$ at $715^{\circ} \mathrm{C}$ is lower than that directly after DPD (cf. Figs. 4a, 6). This suggests that at $715{ }^{\circ} \mathrm{C}$ dislocations annihilate despite the pining effect of nanoparticles.

Very few recrystallised grains appear within the first $10 \mathrm{~min}$ of annealing, but within the next $10 \mathrm{~min}$ (a total annealing time of $20 \mathrm{~min}$ ) recrystallisation progresses very quickly and is almost complete after 80 min (see Figs. 7, 8c). As is evident from Fig. 7, recrystallisation proceeds in such a way that the frequency of $\langle 111\rangle$-oriented grains growing into the recovered environment is greater than the frequency of growing grains of any other orientation. This orientation-dependent recrystallisation leads to a clear predominance of the $\langle 111\rangle$ fibre when the material is almost fully recrystallised (see Figs. 10, 11).

To understand the reason for the observed differences in the annealing behaviour of regions having different orientations, structural parameters of the deformed and recovered material are shown in Fig. 12 separately for the two different texture components. The data in Fig. 12a indicate that after DPD the average boundary spacing within the $\langle 100\rangle$ oriented lamellae is larger $(80 \mathrm{~nm})$ than within the $\langle 111\rangle$-oriented lamellae $(68 \mathrm{~nm})$. After $10 \mathrm{~min}$ of annealing, however, the difference between the average boundary spacings $d_{\theta>2^{\circ}}$ in the recovered $\langle 111\rangle$ and $\langle 100\rangle$-oriented regions is reduced, while after $20 \mathrm{~min}$ of annealing, $d_{\theta>2^{\circ}}$ for the $\langle 111\rangle$-oriented regions is even larger than that for the $\langle 100\rangle$-oriented regions.

Figure $12 \mathrm{~b}$ shows the stored energy density $u$ estimated from the EBSD data for the $\langle 111\rangle$ - and $\langle 100\rangle$ oriented regions in the same deformed and recovered samples. It is seen that in the deformed microstructure $u_{\langle 111\rangle}$ is considerably higher than $u_{\langle 100\rangle}$. This difference can be attributed to the difference in the Taylor factor $M$ between the $\langle 111\rangle$ and $\langle 100\rangle$-oriented regions. According to the pencil-glide model proposed by Taylor, in body-centred cubic metals for grains compressed along $\langle 100\rangle M$ is 2.1 , while for compression along $\langle 111\rangle$ the value of $M$ is 3.2 [30]. Considering that the Taylor factor describes the ratio between the magnitude of accumulated plastic slip and the magnitude of applied strain, the higher Taylor factor for regions of the $\langle 111\rangle$ fibre texture 

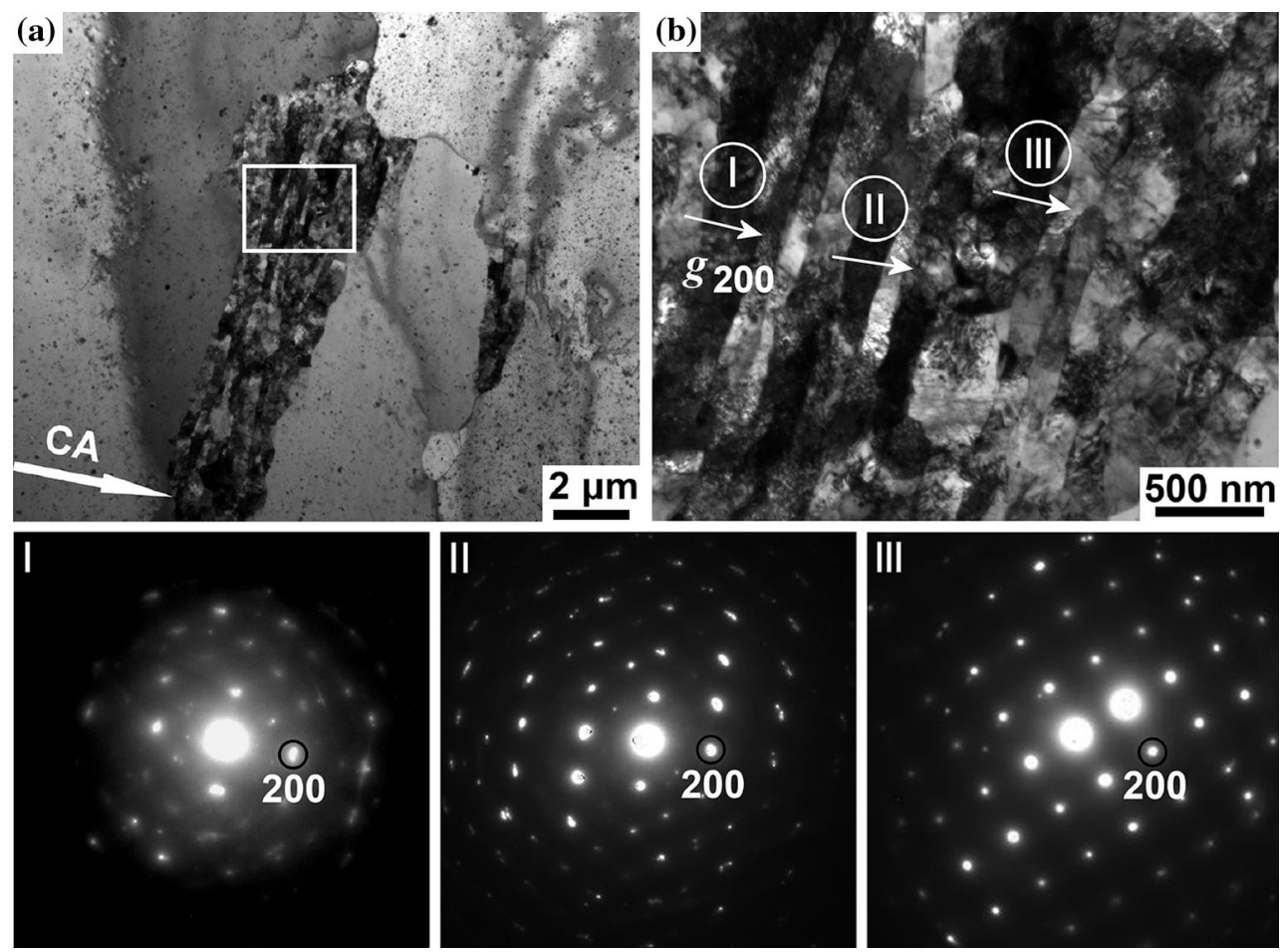

Figure 9 Microstructures of PM2000 after compression by DPD and subsequent annealing at $715^{\circ} \mathrm{C}$ for 80 min: a TEM images showing recrystallised grains and a small non-recrystallised (recovered) region; $\mathbf{b}$ enlarged image of the non-recrystallised region marked by a frame in $\mathbf{a}$. Circles $I, I I$, and $I I I$ in $\mathbf{b}$ indicate

component suggests an increased slip activity in these regions. Consequently, a larger dislocation density and a higher stored energy are expected for the $\langle 111\rangle$-oriented regions compared to the $\langle 100\rangle$ oriented regions, which is fully consistent with the stored energy values obtained for the as-deformed microstructure (see Fig. 12b). Such a higher stored energy in the $\langle 111\rangle$-oriented regions provides a higher driving force for nucleation of recrystallisation, and many more nuclei are formed within the $\langle 111\rangle$-oriented regions. These nuclei have $\langle 111\rangle$ orientations, thus leading to the dominance of the $\langle 111\rangle$ oriented recrystallized grains observed after annealing for $20 \mathrm{~min}$ (see Fig. 7b). The growth of abundant $\langle 111\rangle$-oriented nuclei results in the dominant $\langle 111\rangle$ fibre texture and explains the orientation dependent recrystallisation behaviour. Such a correlation between the Taylor factor, stored energy and preferential nucleation is consistent with previous reports describing the annealing behaviour of body-centred cubic steels after rolling [31-34]. areas from which selected area diffraction patterns were obtained (shown in the lower part of the figure). The $g_{200}$ diffraction vectors are aligned almost parallel to the CA, signifying that crystallographic 200 poles are closely aligned with the CA. The corresponding regions thus belong to the $\langle 100\rangle$ fibre texture. (a)

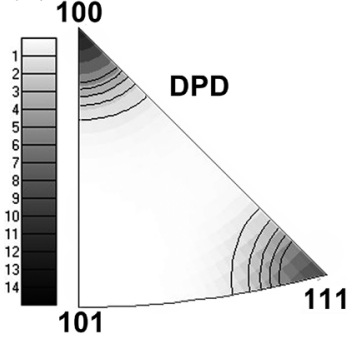

(c)

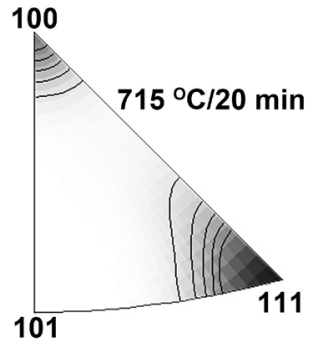

(b)

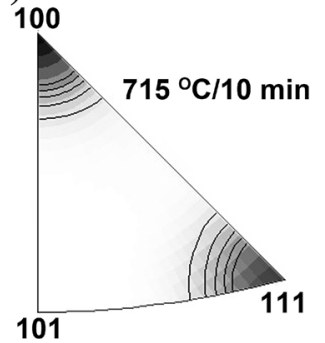

(d)

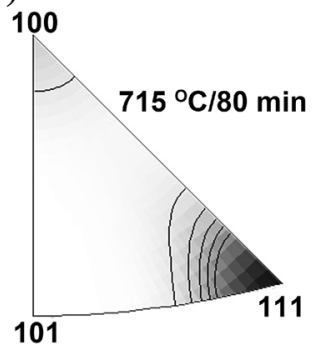

Figure 10 Inverse pole figures showing probability densities for crystallographic directions along the CA in PM2000 after compression by DPD (a), and subsequent annealing at $715^{\circ} \mathrm{C}$ for $10 \mathrm{~min}(\mathbf{b}), 20 \mathrm{~min}(\mathbf{c})$ and $80 \mathrm{~min}(\mathbf{d})$. Contour lines are 1, 2, 3,4 and 5 times random. 
Nevertheless, it should be emphasised that the initially large difference in the stored energy density between $\langle 111\rangle$ - and $\langle 100\rangle$-oriented regions in the deformed condition becomes rather small after annealing for $10 \mathrm{~min}$ at $715^{\circ} \mathrm{C}$. Moreover, after $20 \mathrm{~min}$ the stored energy density within the $\langle 111\rangle$ oriented regions is even lower than of the $\langle 100\rangle$-oriented regions. Obviously, the stored energy density within the $\langle 111\rangle$-oriented regions is reduced during recovery much faster than within regions of the $\langle 100\rangle$ fibre texture component (see Fig. 12b). For nucleation of recrystallisation beyond $10 \mathrm{~min}$, when the stored energy density in both texture components is similar, there might be other reasons for preferred formation of $\langle 111\rangle$-oriented nuclei. One possible reason is that the morphological characteristics of recovered

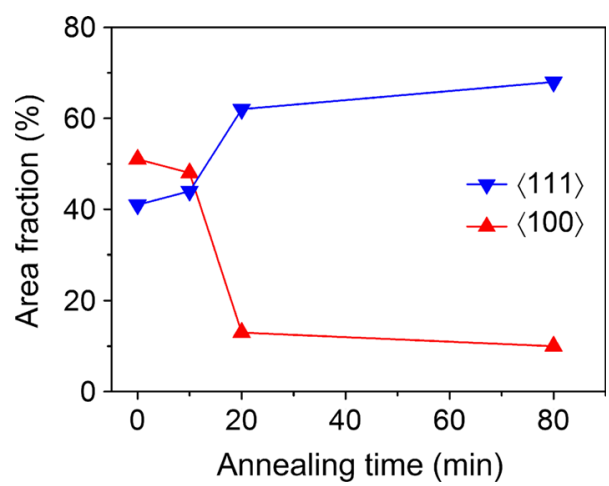

Figure 11 Area fractions of the $\langle 111\rangle$ and $\langle 100\rangle$ fibre texture components in PM2000 after compression by DPD and subsequent annealing at $715^{\circ} \mathrm{C}$.

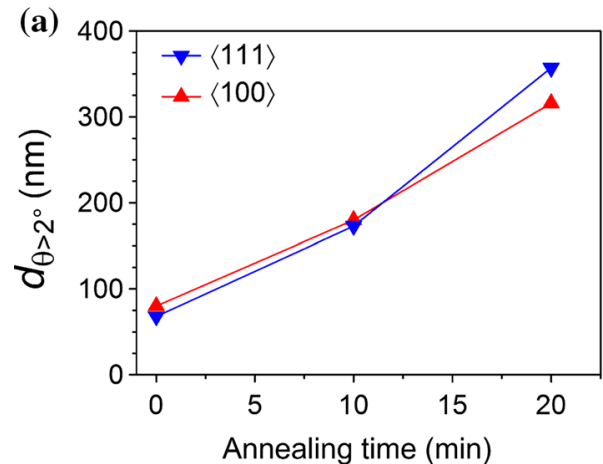

Figure 12 Changes in deformed and recovered regions of either $\langle 111\rangle$ or $\langle 100\rangle$ fibre texture components in PM2000 after compression by DPD and subsequent annealing at $715^{\circ} \mathrm{C}$ : subgrains may be different for the $\langle 111\rangle$ component and the $\langle 100\rangle$ component [29]. Considering that rather straight lamellar boundaries are still observed within recovered $\langle 100\rangle$-oriented regions even after 80 min at $715{ }^{\circ} \mathrm{C}$ (Fig. 9), it is reasonable to suggest that the recovered lamellar structure impedes the formation of nuclei in these regions.

\section{Concluding remarks}

Compression of PM2000 by DPD to a strain of 2.1 significantly refines the initial microstructure by nanoscale lamellae having a duplex $\langle 111\rangle+\langle 100\rangle$ fibre texture. The strength of material increases substantially, whereas the thermal stability of the nanostructured material is reduced. This reduced thermal stability is attributed to a high density of dislocations and dislocation boundaries induced by DPD. In the as-deformed microstructure, the stored energy density estimated from the EBSD data is found to be higher in the $\langle 111\rangle$-oriented regions than in the $\langle 100\rangle$-oriented regions. Recovery during annealing at $715{ }^{\circ} \mathrm{C}$ reduces the energy stored in the deformed microstructure, and this reduction is more pronounced in the $\langle 111\rangle$-oriented regions. Orientation-dependent recrystallisation takes place in the recovered microstructure, leading to the strengthening of the $\langle 111\rangle$ fibre texture component at the expense of the $\langle 100\rangle$ fibre texture component. As a result, a strong $\langle 111\rangle$ fibre texture is observed when recrystallisation is almost complete.

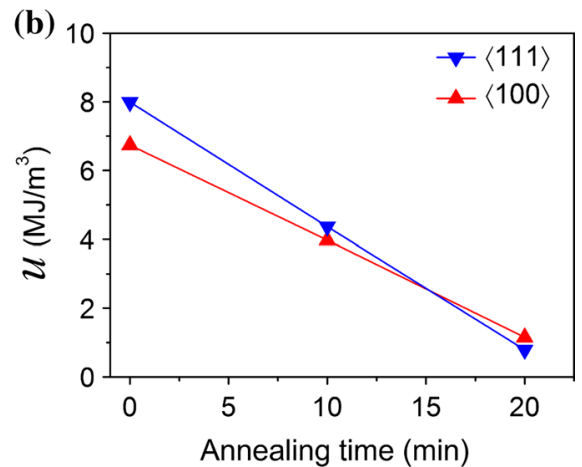

a average boundary spacing $d_{\theta>2^{\circ}}$ along the CA; b stored energy density $u$ calculated from the EBSD data. 


\section{Acknowledgements}

Financial support from the Sino-Danish Center for Education and Research is gratefully acknowledged. The authors are grateful to Prof. M. Heilmaier for providing the initial PM2000 sample.

Open Access This article is distributed under the terms of the Creative Commons Attribution 4.0 International License (http://creativecommons.org/ licenses/by/4.0/), which permits unrestricted use, distribution, and reproduction in any medium, provided you give appropriate credit to the original author(s) and the source, provide a link to the Creative Commons license, and indicate if changes were made.

\section{References}

[1] Odette GR, Alinger MJ, Wirth BD (2008) Recent developments in irradiation-resistant steels. Annu Rev Mater Res 38:471-503

[2] Charit I, Murty KL (2010) Structural materials issues for the next generation fission reactors. JOM 62:67-74

[3] Song M, Wu YD, Chen D, Wang XM, Sun C, Yu KY, Chen Y, Shao L, Yang Y, Hartwig KT, Zhang X (2014) Response of equal channel angular extrusion processed ultrafinegrained T91 steel subjected to high temperature heavy ion irradiation. Acta Mater 74:285-295

[4] Shen TD, Feng S, Tang M, Valdez JA, Wang Y, Sickafus KE (2007) Enhanced radiation tolerance in nanocrystalline $\mathrm{MgGa}_{2} \mathrm{O}_{4}$. Appl Phys Lett 90:263115

[5] Hansen N (1990) Cold deformation microstructures. Mater Sci Technol 6:1039-1047

[6] Hansen N, Juul Jensen D (2011) Deformed metals - structure, recrystallisation and strength. Mater Sci Technol 27:1229-1240

[7] Song M, Sun C, Jang J, Han CH, Kim TK, Hartwig KT, Zhang X (2013) Microstructure refinement and strengthening mechanisms of a $12 \mathrm{Cr}$ ODS steel processed by equal channel angular extrusion. J Alloys Compd 577:247-256

[8] Zhang ZB, Mishin OV, Tao NR, Pantleon W (2015) Microstructure and annealing behavior of a modified $9 \mathrm{Cr}$ 1 Mo steel after dynamic plastic deformation to different strains. J Nucl Mater 458:64-69

[9] Li YS, Tao NR, Lu K (2008) Microstructural evolution and nanostructure formation in copper during dynamic plastic deformation at cryogenic temperatures. Acta Mater $56: 230-241$

[10] Huang F, Tao NR, Lu K (2011) Effects of strain rate and deformation temperature on microstructures and hardness in plastically deformed pure aluminum. J Mater Sci Technol $27: 1-7$

[11] Luo ZP, Mishin OV, Zhang YB, Zhang HW, Lu K (2012) Microstructural characterization of nickel subjected to dynamic plastic deformation. Scr Mater 66:335-338

[12] Schneibel JH, Heilmaier M, Blum W, Hasemann G, Shanmugasundaram $\mathrm{T}$ (2011) Temperature dependence of the strength of fine- and ultrafine-grained materials. Acta Mater 59:1300-1308

[13] Zhang ZB, Mishin OV, Tao NR, Pantleon W (2015) Effect of dynamic plastic deformation on microstructure and annealing behaviour of modified $9 \mathrm{Cr}-1 \mathrm{Mo}$ steel. Mater Sci Technol 31:715-721

[14] Humphreys FJ (2001) Review grain and subgrain characterisation by electron backscatter diffraction. J Mater Sci 36:3833-3854. doi:10.1023/A:1017973432592

[15] Godfrey A, Mishin OV, Liu Q (2006) Processing and interpretation of EBSD data gathered from plastically deformed metals. Mater Sci Technol 22:1263-1270

[16] Wu GL, Juul Jensen D (2008) Automatic determination of recrystallization parameters based on EBSD mapping. Mater Charact 59:794-800

[17] Godfrey A, Cao WQ, Hansen N, Liu Q (2005) Stored energy, microstructure, and flow stress of deformed metals. Metall Mater Trans A 36A:2371-2378

[18] Godfrey A, Hansen N, Juul Jensen D (2007) Microstructural-based measurement of local stored energy variations in deformed metals. Metall Mater Trans A 38A:2329-2339

[19] Humphreys FJ, Hatherly M (2004) Recrystallization and related annealing Phenomena. Elsevier, Oxford

[20] Read WT, Shockley W (1950) Dislocation models of crystal grain boundaries. Phys Rev 78:275-289

[21] Read WT (1953) Dislocations in crystals. McGraw-Hill, New York, pp 155-172

[22] Zhang ZB, Mishin OV, Tao NR, Pantleon W (2014) Evolution of oxide nanoparticles during dynamic plastic deformation of ODS steel. In: Fæster S et al (Eds.), Proc 35th Risø Int Symp Mater Sci, p. 423-430

[23] Barlow CY, Hansen N (1989) Deformation structures in aluminum containing small particles. Acta Metall 37:1313-1320

[24] Dillamore IL, Katoh H, Haslam K (1974) The nucleation of recrystallisation and the development of textures in heavily compressed iron-carbon alloys. Texture 1:151-156

[25] Hu H (1974) Texture of metals. Texture 1:233-258

[26] Klueh RL, Shingledecker JP, Swindeman RW, Hoelzer DT (2005) Oxide dispersion-strengthened steels: a comparison of some commercial and experimental alloys. J Nucl Mater 341:103-114

[27] Song R, Ponge D, Raabe D, Speer JG, Madock DK (2006) Overview of processing, microstructure and mechanical 
properties of ultrafine grained bcc steels. Mater Sci Eng A 441:1-17

[28] Zhang YB, Mishin OV, Kamikawa N, Godfrey A, Liu W, Liu Q (2013) Microstructure and mechanical properties of nickel processed by accumulative roll bonding. Mater Sci Eng A 576:160-166

[29] Zhang ZB (2015) Nanostructures in a ferritic and an oxide dispersion strengthened steel induced by dynamic plastic deformation. PhD dissertation. Technical University of Denmark

[30] Rosenberg JM, Piehler HR (1971) Calculation of the Taylor factor and lattice rotations for bcc metals deforming by pencil glide. Metall Trans 2:257-259
[31] Every RL, Hatherly M (1974) Oriented nucleation in lowcarbon steels. Texture 1:183-194

[32] Hutchinson WB (1984) Development and control of annealing textures in low-carbon steels. Int Mater Rev 29:25-42

[33] Samajdar I, Verlinden B, Van Houtte P, Vanderschueren D (1997) $\gamma$-fibre recrystallization texture in IF-steel: an investigation on the recrystallization mechanisms. Mater Sci Eng A 238:343-350

[34] Gazder AA, Sanchez-Araiza M, Jonas JJ, Pereloma EV (2011) Evolution of recrystallization texture in a $0.78 \mathrm{wt} \%$ $\mathrm{Cr}$ extra-low-carbon steel after warm and cold rolling. Acta Mater 59:4847-4865 